\title{
Effect of Cannabis Legalization on US Autism Incidence and Medium Term Projections
}

\author{
Albert Stuart Reece ${ }^{1,2 *}$, Gary Kenneth Hulse ${ }^{1,2}$ \\ ${ }^{1}$ Division of Psychiatry, University of Western Australia, Crawley, Western Australia 6009, Australia; ${ }^{2}$ School of Medical and Health \\ Sciences, Edith Cowan University, Joondalup, Western Australia, 6027, Australia
}

\begin{abstract}
Objective: In that cannabis use has been linked with the development of autism spectrum disorder like conditions in gestationally exposed children, we set out to explore the extent to which rising cannabis use might contribute to the rising autism epidemic.

Methods: Datasets from US Department of Education Individuals with Disabilities Act (IDEA), National Survey of Drug Use and Health, and CDC's Autism and Developmental Disabilities Monitoring (ADDM) Network were investigated. Data on legal status was derived from SAMHSA.

Results: IDEA had N=1,023 and ADDM N=87. Modelling of IDEA consistently showed that models quadratic-intime out-performed linear-only models (ANOVA $\mathrm{p}<2.0 \times 10^{-16}$ ). In both datasets liberalization of cannabis legislation was associated with increased ASD $\left(\mathrm{p}<10^{-9}\right.$ and $\mathrm{p}<0.05$ respectively). Slopes of: ASD vs. time, Cannabis vs. time and ASD vs. cannabis curves were shown to be related on graphical analysis by geofacet plots and tanglegrams (entanglement=0.3326). CDC's ADDM network quoted US autism incidence 168/10,000 in 2014. IDEA projections indicated rates 108.57, 131.67 and 166.49 in cannabis-illegal, -medical and -decriminalized states rising exponentially to 282.37, 396.91 and 455.54 by 2030.

Conclusion: ASD is the commonest form of cannabis-associated clinical teratology. Using two independent datasets and two categorization methods we confirmed that medical, decriminalized and legal cannabis regimes are associated with higher rates of ASD than illegal ones. Findings are consistent with molecular, cellular and epigenetic mechanisms. Formerly quadratic regression curves become exponential when projected forwards to 2030; predict a lower quantum than the 2014 ADDM CDC figure; and indicate a 60\% excess of cases in legal states by 2030.

Keywords: Cannabis; Cannabinoids; Cannabidiol; Cannabinol; Cannabichromene; Tetrahydrocannabinol

Abbreviations: ADDM: Autism and Developmental Difficulties Monitoring from CDC; ASD: Autism Spectrum Disorder; CB1R: Cannabinoid Type 1 Receptor; CDC: Centers for Disease Control; IDEA: US Department of Education Individuals with Disabilities Act; NSDUH: National Survey of Drug Use and Health; Robo: Roundabout, a guidance molecule receptor for axonal growth cones and arterial endothelial tips; SAMHSA: Substance Abuse and Mental Health Services Administration; Slit: Slits 1-3, arterial and axonal guidance molecule and ligand for Robo; + : An additive operator for regression calculations; : Tilde, a middle sign separating the two sides of a regression calculation; *: Asterisk, an operator used in regression calculations to include additive and interactive relationships.
\end{abstract}

\section{INTRODUCTION}

Recent reports from several sources indicate that the incidence of Autistic Spectrum Disorder (ASD) has been growing significantly in most USA jurisdictions in recent decades [1-3]. Although the cause is not completely understood, periconceptual and perigestational exposures including genetic and epigenetic factors are believed to play an important role [4-6]. Older parents, affected siblings, time between births, exposure to some drugs, particularly anticonvulsants and SSRI antidepressants and folic acid deficiency

Correspondence to: Albert Stuart Reece, Division of Psychiatry, University of Western Australia, Crawley, Western Australia 6009, Australia, Tel: (617) 3844-4000; Fax: (617) 3844-4015, E-mail: stuart.reece@bigpond.com

Received: April 15, 2019, Accepted: Apri 26, 2019, Published: May 03, 2019

Citation: Reece AS, Hulse GK. (2019) Effect of Cannabis Legalization on US Autism Incidence and Medium Term Projections. Clin Pediatr OA 4:154

Copyright: $\odot 2019$ Reece AS, et al. This is an open-access article distributed under the terms of the Creative Commons Attribution License, which permits unrestricted use, distribution, and reproduction in any medium, provided the original author and source are credited. 
have all been implicated [4-6]. So too has cannabinoid exposure $[7,8]$.

This opens the possibility that the recent rise in the use of cannabinoids across the USA may be linked to the disturbing rise in the prevalence of autism [9]. Such a link achieves public health importance in the light of large numbers of pregnant American women who are exposed to cannabis, reaching 161,000 in 2017 [10]. The frequent recommendation of cannabis dispensaries to pregnant users to consume cannabis during gestation [11], and the positive test or affirmation of cannabis use by $25 \%$ of Californian teenage mothers [12].

The USA provides a useful opportunity to epidemiologically assess the putative association of cannabis in autism pathogenesis as the Substance Abuse and Mental Health Services Administration (SAMHSA) report strong negative trends for all other drug use in USA, but strong upward trends in cannabis use across the country $[10,13]$. This has the effect at the epidemiological level of isolating the effect of cannabis in statistical analyses.

Given that a number of leading USA public health organisations have published data showing that pro-cannabis legalization paradigms are associated with increased rates of cannabis use [14], we investigated if these trends in individual states cannabis use were associated with increased incidence of ASD. The reader should note that it is our view that a putative link between prenatal cannabis use and ASD is already established by both mechanistic and longitudinal epidemiological studies which have been published in the literature. The question we set out to address was to what extent these putative relationships might be reflected in the extant epidemiological data on this subject.

\section{METHODS}

\section{Data}

Data on autism incidence rates at eight years of age was obtained from two sources. The major source was the US Department of Education Individuals with Disabilities Act (IDEA) Network and was sourced from [3]. The Network for Autism and Developmental Disabilities Monitoring (ADDM) based at CDC was also accessed from $[2,3]$. The IDEA dataset includes 1,023 points in 51 US states including the District of Columbia at annual intervals from 19912011. The ADDM dataset includes 87 data points 2000-2014 in selected states in eight cycles at two yearly intervals. As one metric is derived from schools and the other from clinical services the two rates used are not directly comparable.

Data on drug use was sourced from the National Survey of Drug Use and Health (NSDUH), which is an annual household survery conducted by SAMHSA [10]. Data on the legal status of cannabis in the various US states was derived from two sources, firstly an internet search of historical sources, and secondly an address by the Director of SAMHSA on $4^{\text {th }}$ February 2019 [15] which provided details on the legal status of cannabis by state at that time.

\section{Statistics}

Desktop R from CRAN v3.5.2 was used for all analyses which were done in $\mathrm{R}$ Studio 1.1 .463 , performing regressions and preparing graphs and maps. Continuous variables were log transformed to optimize normality assumptions as guided by the Shapiro test. Linear regression was conducted in the classical manner by progressive manual model reduction by deletion of the least significant term. Model diagnostics were checked in each case in R. Geofacetted graphs were prepared using the geofacet package v0.1.9 and tanglegrams (interacting dendrograms) were prepared using dendextend v0.1.9 and cluster v2.0.7.1 and factoextra v1.0.5 amongst other packages. Bivariate choropleth maps were prepared using the colorplaner package v0.1.4 and ggplot2 v3.1.0. The R function predict in the stats package which comes with Base $\mathrm{R}$ was used for simple model forward projections. $\mathrm{p}<0.05$ was considered significant.

\section{Ethics}

Ethical permission to undertake this study was granted from the Human Research Ethics Committees of the Southcity Medical Centre and the University of Western Australia.

\section{RESULTS}

Figure 1 presents choropleth maps of cannabis use, ASD and both cannabis and autism together across USA by state. Figure $1 \mathrm{C}$ is a bivariate choropleth map. Purple and pink shading indicate regions where both cannabis and autism are high such as California, Oregon and Vermont. Most of the bivariate map is green indicating that both signals are simultaneously low.

The time courses of both cannabis and autism (IDEA data) are presented for each US state in Supplementary Figures 1-4. Supplementary Figure 1 shows the time course of autism in 25 states with names from $\mathrm{A}$ to $\mathrm{M}$ plotted on an ordinate axis which is constant throughout. Supplementary Figure 2 shows a similar plot for the remaining 24 states with names from $\mathrm{M}$ to $\mathrm{W}$. Supplementary Figure 3 shows the last month cannabis use rate for states over time for the alphabetically first 25 US states A to M. Supplementary Figure 4 shows similar cannabis use data for states $\mathrm{M}$ to W.

Figure 2 is a geofacetted plot showing the time course of autism rates and cannabis use, both of which have been scaled to make them comparable. The advantage of this format is that the data for each state appears separately and overplotting does not occur. Readers who may be interested in a particular American state can readily examine the pattern in their state and how this compares to that seen in nearby states. The figure clearly shows evidence of rising cannabis use rates and concurrently rising autism states in most states. This pattern is emphasized by the inclusion of regression lines for each plot.

Figure 3 shows the IDEA data categorized by legal status firstly by data from SAMHSA (A) and secondly using historical documentation of when each state transitioned into medical or legal use derived from an internet search (B). In each case the figures show clear separation of the autism rate in each legal category. This graphical demonstration suggests analysis by transformed autism rate over time.

Table 1 presents some of the regressions from Figure 3A, many of which achieve high levels of statistical significance. Figure $3 \mathrm{~A}$ appears to be of quadratic form and one notes in Table 1 that the R-squared values are higher for regressions quadratic in time rising from about 0.78 to about 0.82 . This superiority is confirmed at Anova testing (AIC-linear=321.89, AIC-Quadratic $=272.30, \mathrm{dF}=1$, $\left.\mathrm{F}=185.63, \mathrm{p}<2.0 \times 10^{-16}\right)$.

Table 2 presents the results of the linear regressions from Figure 3B. 


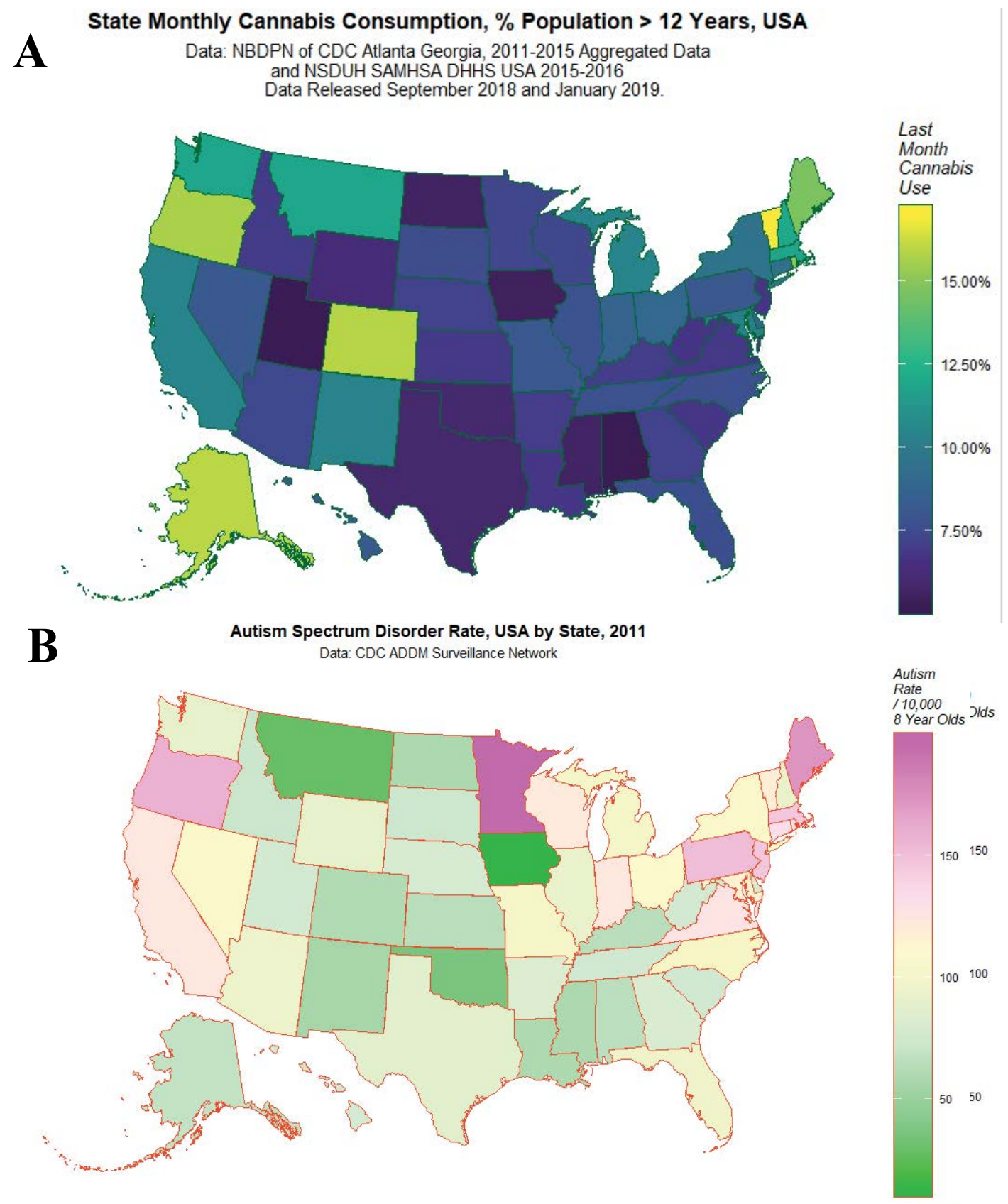

\section{Autism Spectrum Disorder Rate, USA by State, 2011 Bivariate Choropleth Colorplane Map}

CDC ADDM Network, Atlanta Georgia and NSDUH SAS Datafile SAMHSA DHHS USA
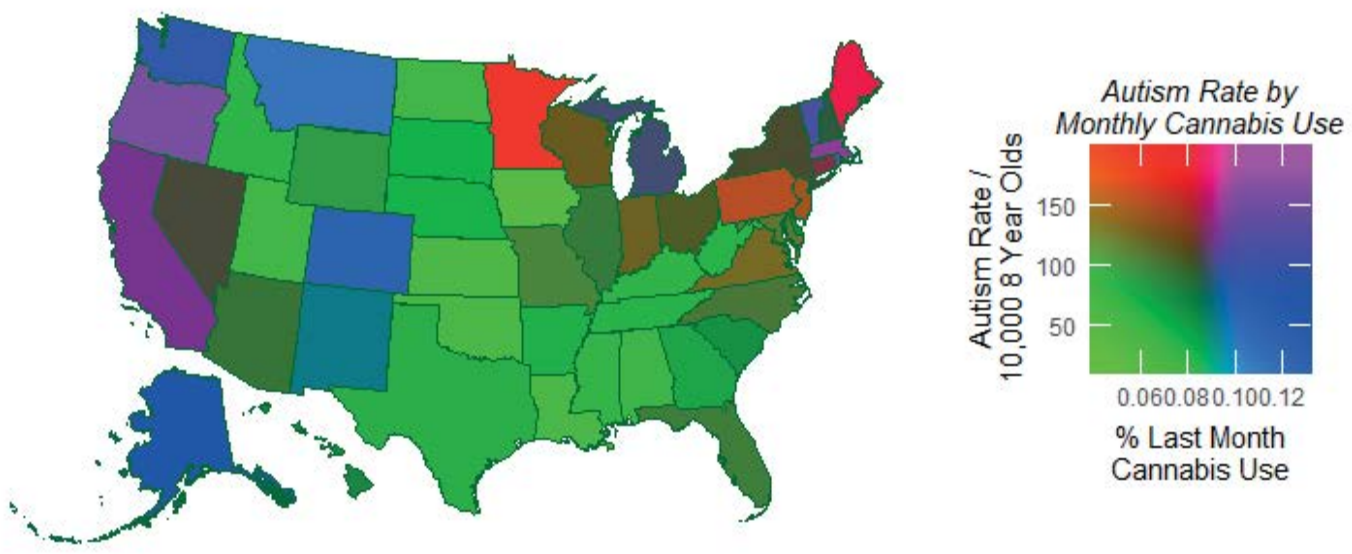

Figure 1: Maps of A: Cannabis Use, B: Autism, C: Cannabis use and autism together by USA state. 


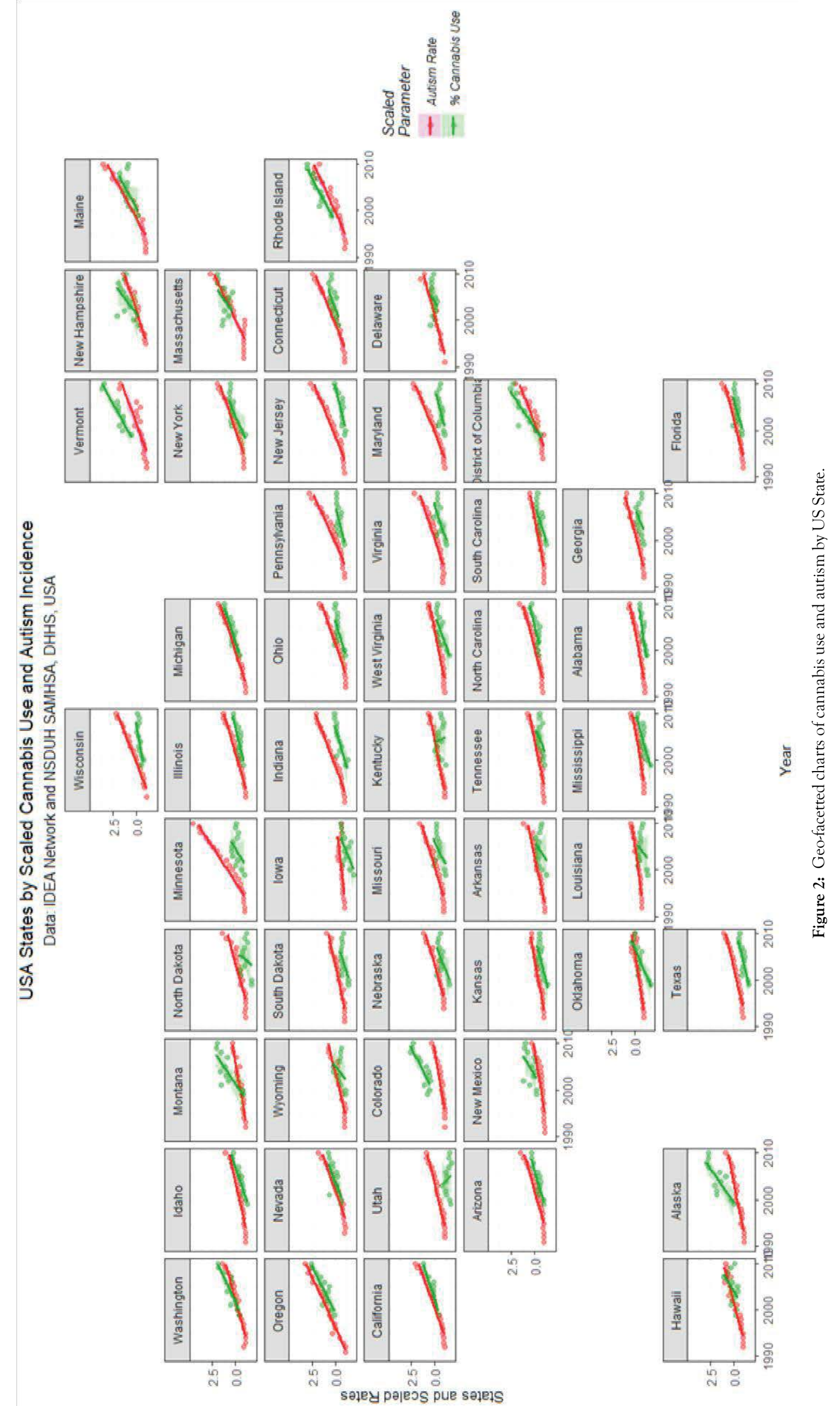




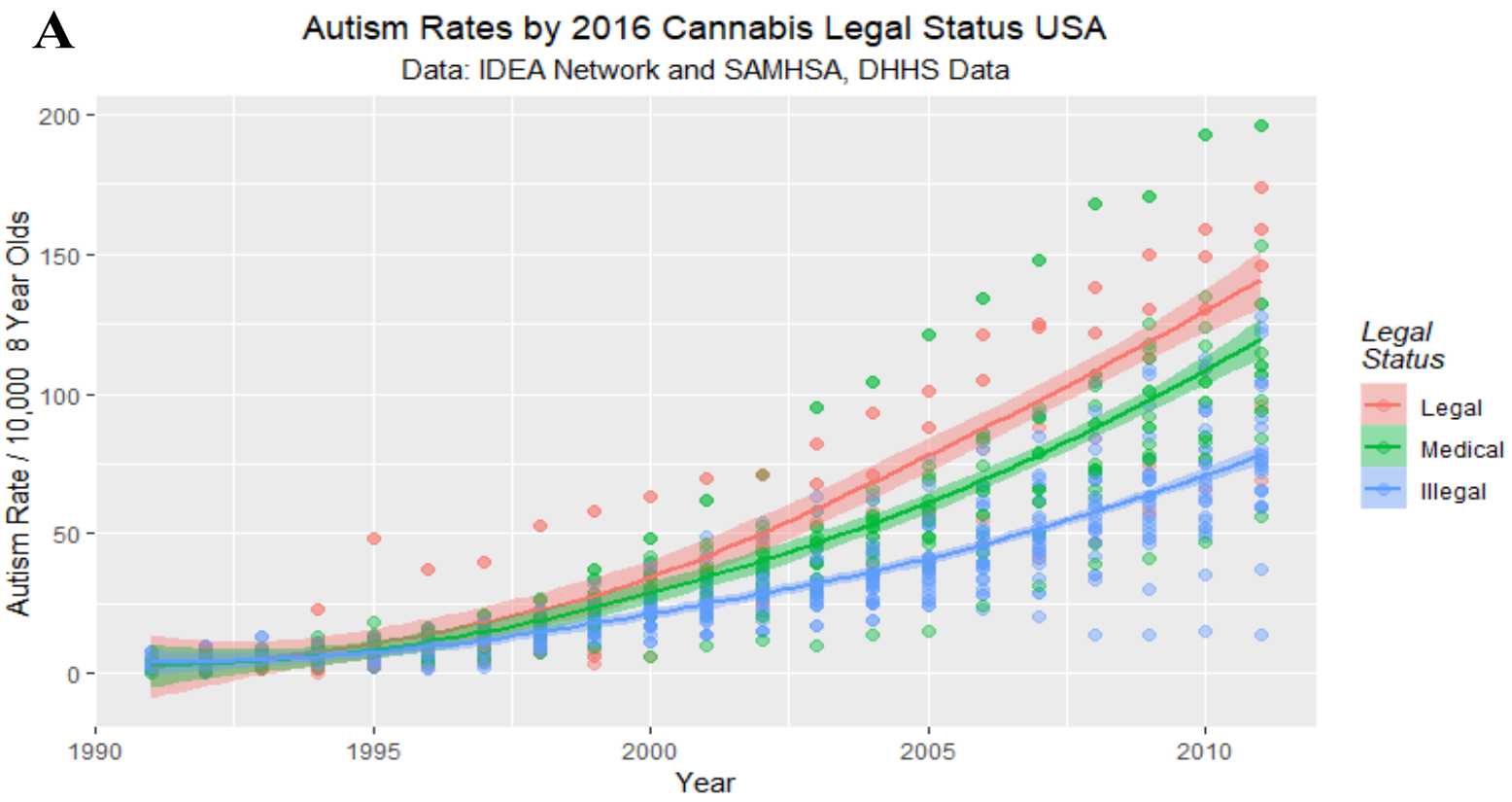

\section{B Autism Rates by Cannabis Legal Status Over Time, USA} Data: USA IDEA Network and Historical Data

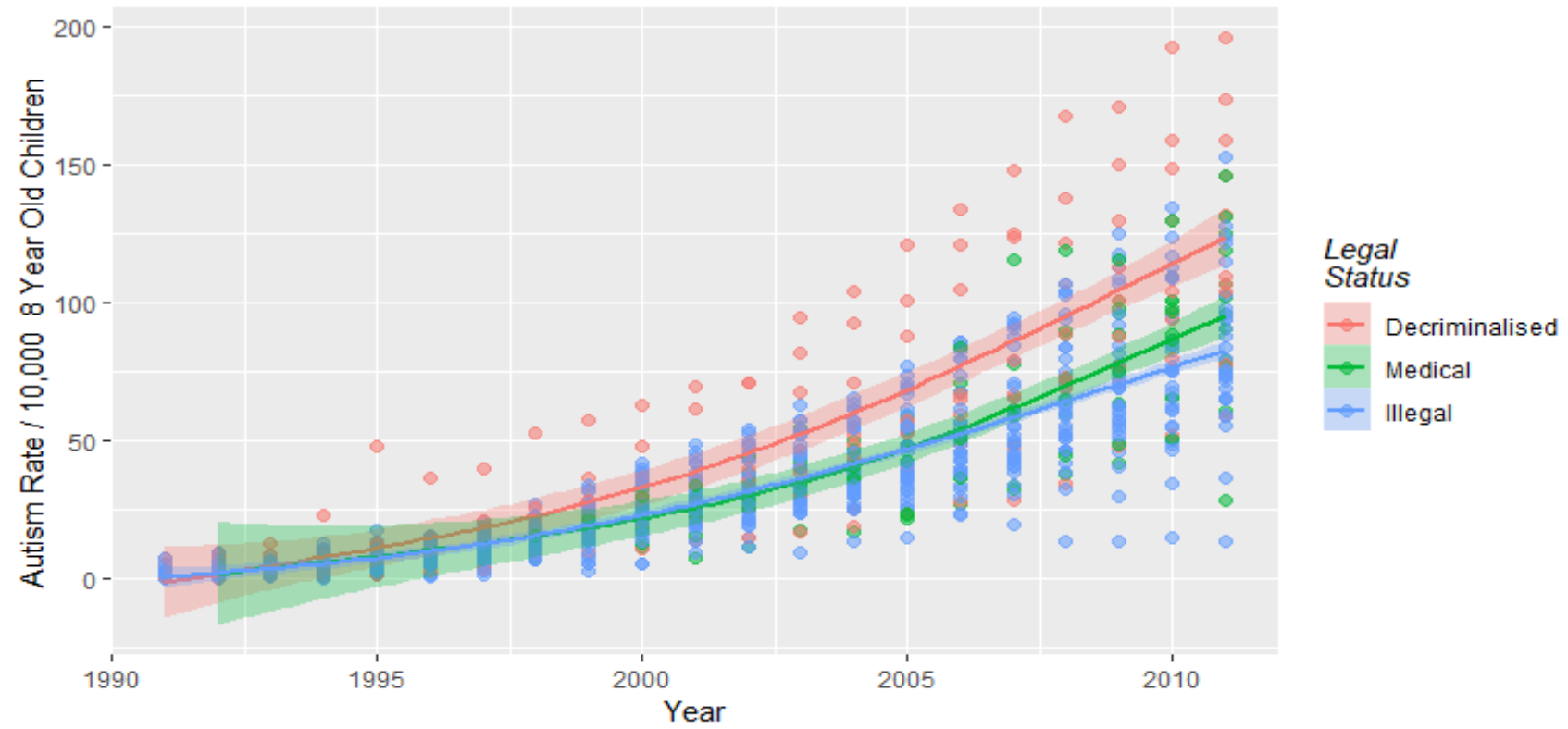

Figure 3: Graphs of Autism by US state by cannabis legal status using A: SAMHSA described legal status and B: historical legal status.

Again quadratic models are superior (ANOVA: AIC-linear=306.43, AIC-Quadratic $\left.=255.23, \mathrm{dF}=3, \mathrm{~F}=51.19, \mathrm{p}<2.0 \times 10^{-16}\right)$.

Figure 4 shows some graphical dissections of the ADDM data on autism incidence. Figure 4A shows the ASD rate over time for the fifteen states in the CDC ADDM network with individual regression lines of best fit. Figure 4B shows similar data with a loess localized polynomial curve fitted to all the states as one whole dataset. Figure $4 \mathrm{C}$ presents the same data with a single least squares regression line for all the data. Figure $4 \mathrm{D}$ is a similar plot but this time with the states categorized into states where cannabis is illegal and states where cannabis is legal for medical or recreational use. Panel D illustrates a dichotomized stratification of legal status which is shown in Table 3 to be significant.

Since it has been shown that cannabis legalization is associated with more widespread cannabis use [14] it is of interest to consider the relationship between the slope of the cannabis use curves and the slopes of the autism rise. Figure 5 is a geofacetted plot which presents the very important data of the autism rate as a function of community uptake of cannabis by state. Several important features stand out from this graph. States charted in red and pink, particularly Maine, Minnesota, Oregon and Ohio seem either to have higher levels of autism or to be rising more steeply. Secondly in most cases the slopes of the regression lines showing the relation between the autism rate and cannabis use rate is positive irrespective of the legal status of cannabis. This is a very important finding indeed.

This finding is so important that it is again investigated in Figure 6 which compares the slopes of the regression lines by state for autism against time squared against each line's intercept on a single plot. This is a common plot used by statisticians to investigate models. 
Table 1: Linear Regression of IDEA Database on 2018 Cannabis Status.

Parameter

\section{IDEA}

\section{Linear Models}

Log (Autism_Rate)_Status

Status Medica

Status Legal

Log (Autism_Rate)_Time+Status

Year

Status Medical

Status Legal

Log (Autism_Rate) Time * Status

Year

Year: Status Legal

Status Legal

Year: Status Medical

Status Medical

Quadratic Models

Log(Autism_Rate)_(Time $)^{2}+$ Status

Time

(Time) $)^{2}$

Status_Medical

Status_Legal

Log(Autism_Rate)_(Time $)^{2}$ * Status

Time

$(\text { Time })^{2}$

Status_Medical

Status_Legal

Time: Status_Legal

$(\text { Time })^{2}$ : Status_Medical

Time: Status_Legal
Parameters

$\begin{array}{llll}\text { Est. } & \text { Std. Error } \mathrm{t} \text { value } \operatorname{Pr}(>|\mathrm{t}|) \quad \text { Adj. } \mathrm{R} \mathrm{Sq}\end{array}$
Model

F df P



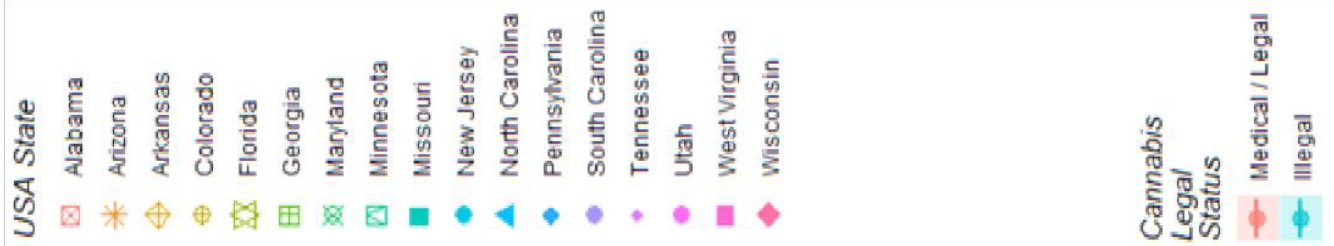

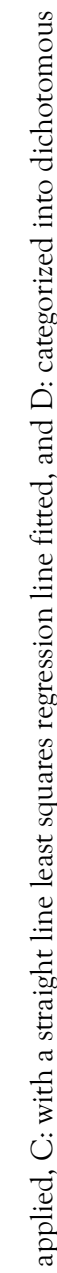

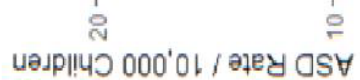

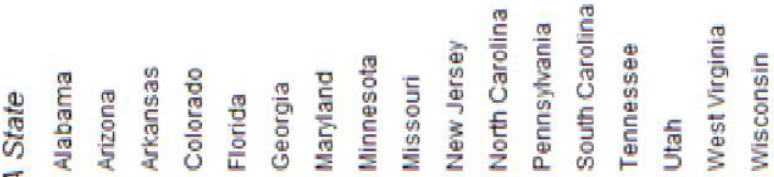

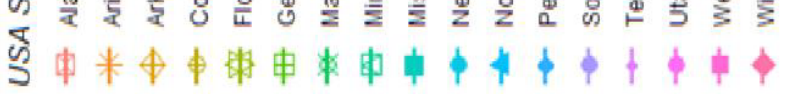

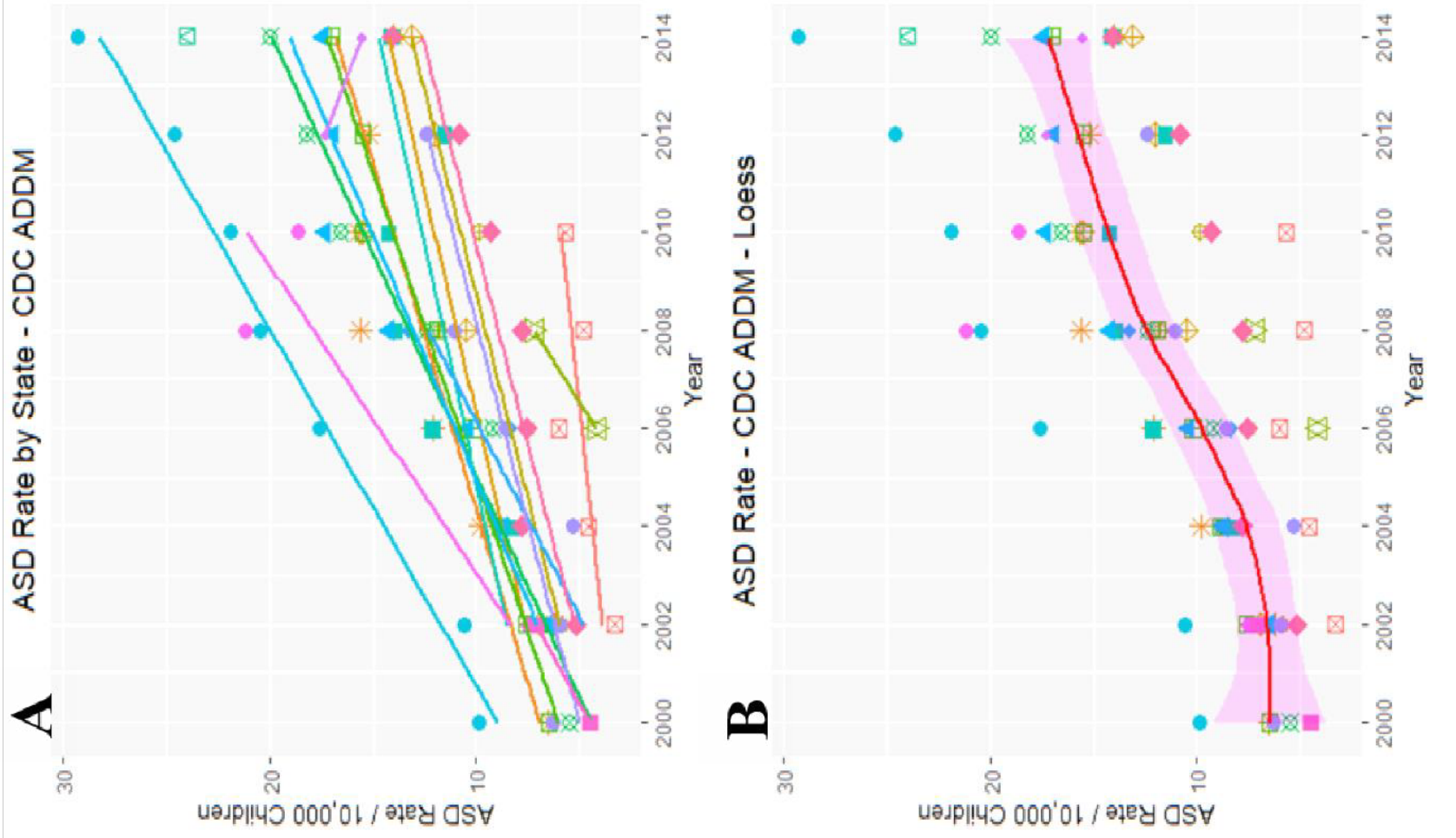




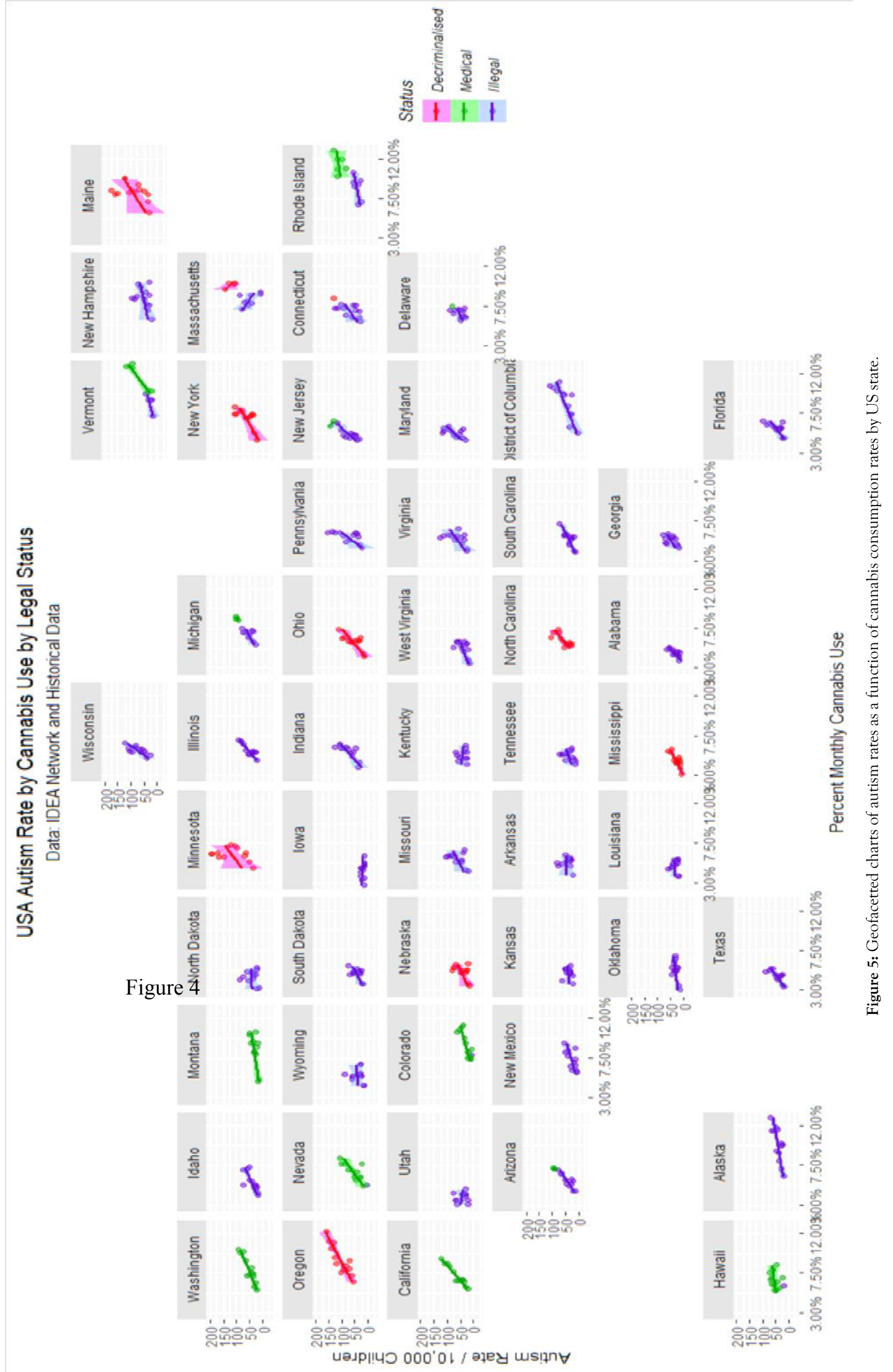




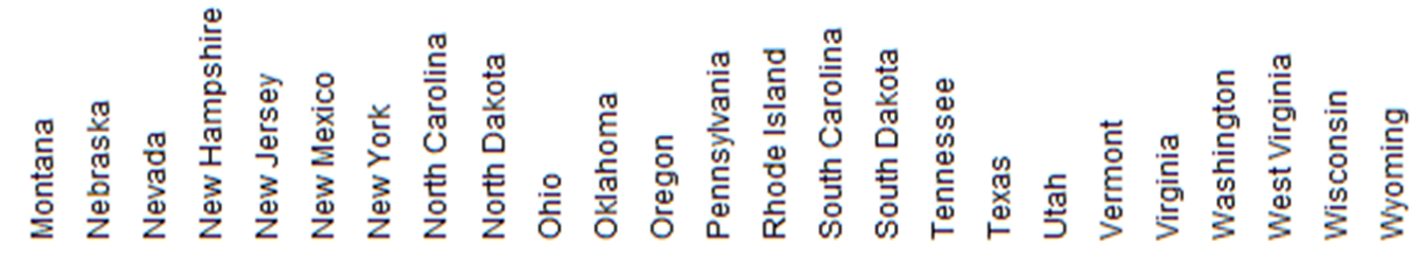

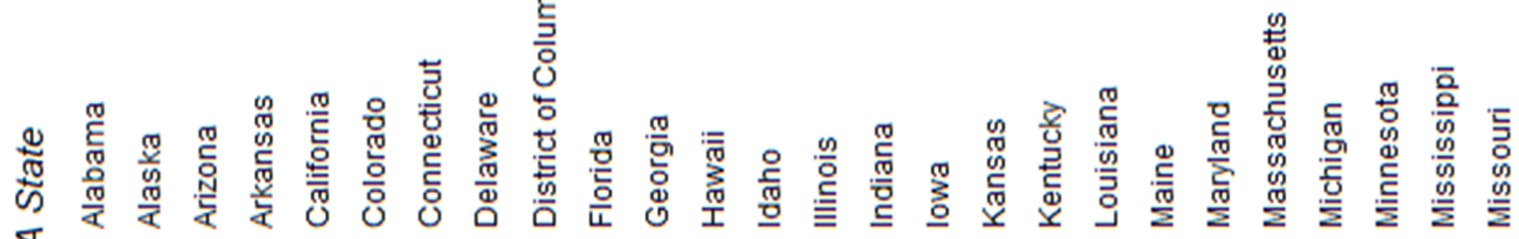
赵

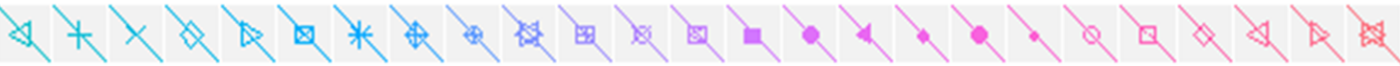
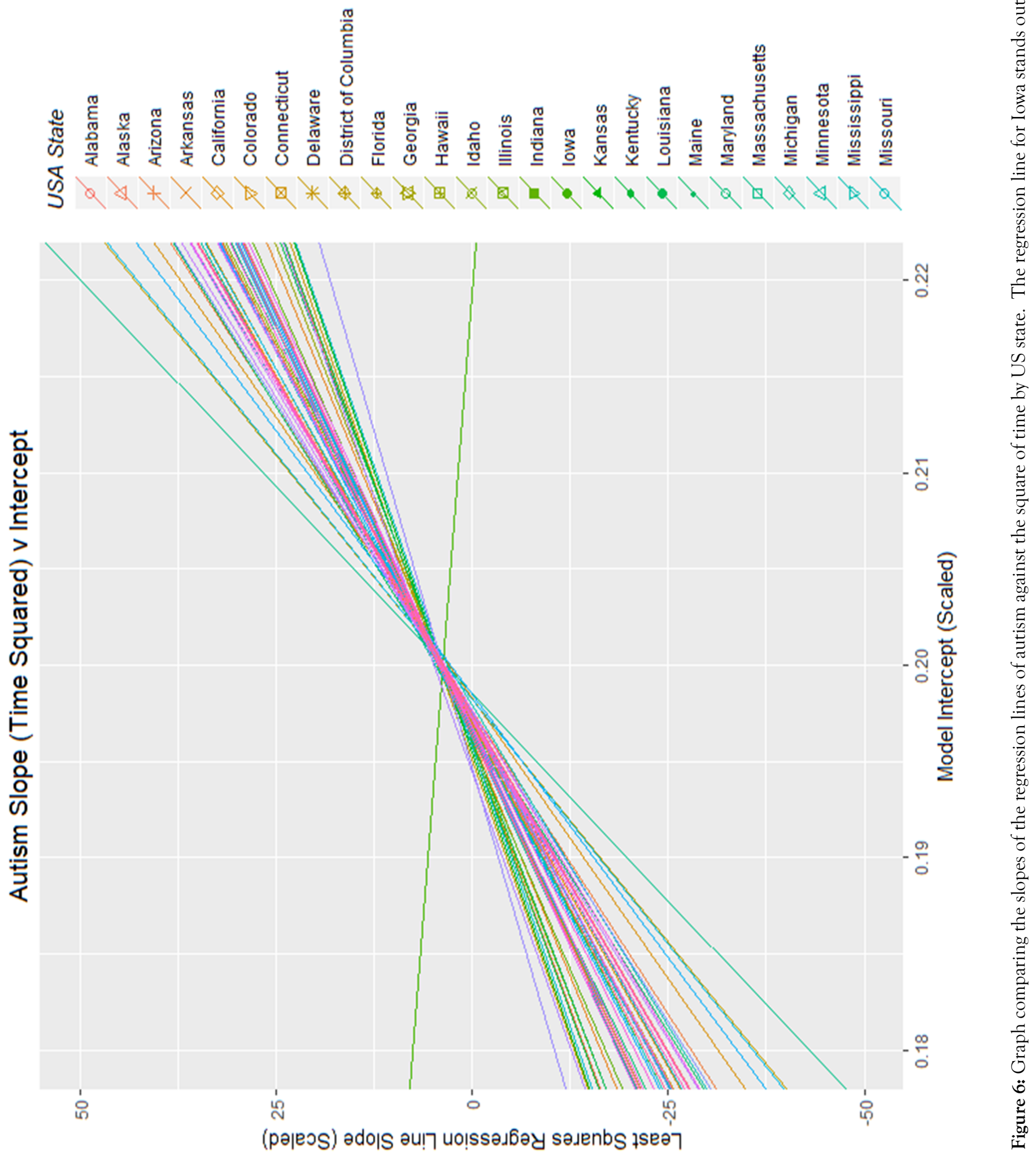
The negative slope in Iowa stands out prominently when the data is presented in this manner. The slope of the autism rate against time (squared) is noted to be positive in 48 of 49 states.
If cannabis use and autism were causally related it might be reasonable to suppose that the rates of rise of the slopes of the two regression lines might be roughly parallel. Figure 7 plots two interacting cluster dendrograms classifying the slope of the autism

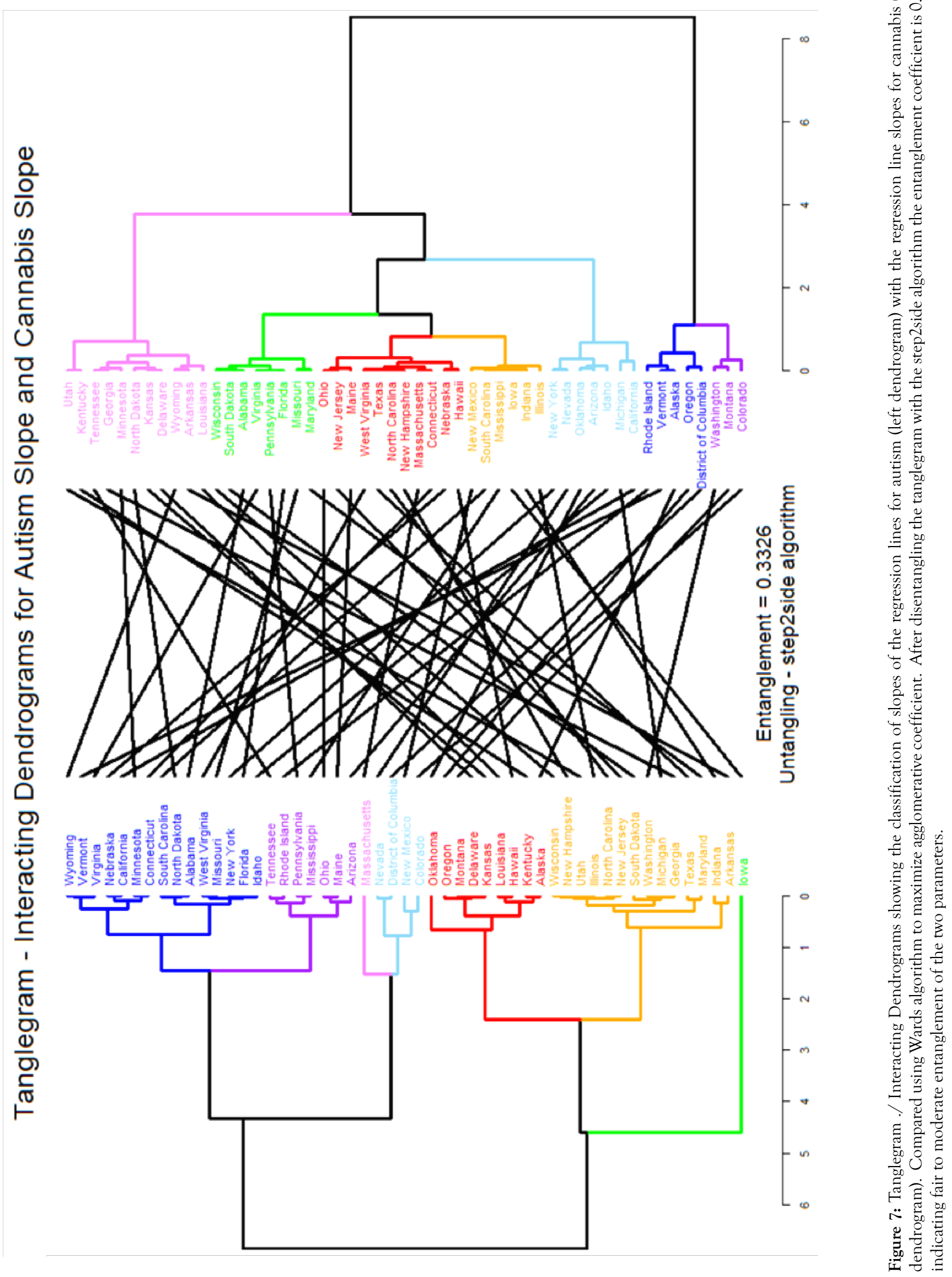


regression lines on the left and cannabis use regression slope on the right. The dendrograms have been drawn using Ward's algorithm to perform hierarchical clustering which achieved the highest agglomerative coefficient $(\mathrm{AC}=0.9727 \mathrm{v} 0.9657$ from the complete method with all the others lower). When an untangling algorithm (step 2 side) is applied to these two dendrograms the two are shown to be fairly-to-moderately entangled (entanglement coefficient $=0.3326$ ). This coefficient is a measure of the statistical relationship between the two dendrograms.

Figure 8 again presents the IDEA autism frequency data by time together with the various applicable quadratic equations for the curves of best fit for each legal condition. In each case the curve of best fit is shown for each legal category of cannabis use.
One notes that ascertainment of rates of autism can be very delayed after birth and it is not uncommon to wait until children are eight years of age before finalizing such a diagnosis. This introduces a protracted delay into case finding and tracking of the epidemic. Hence the IDEA dataset finishes in 2011, but we are already at 2019 at the time of writing.

Since the IDEA dataset is so rich it lends itself to simple forward projections. This has been done using the predict function from the stats package in R. Figure 9 shows that the previously quadratic curves now appear to be exponential, and this is confirmed on formal testing (equations presented on the figure for each legal category; R-squared for exponential models for decriminalization, medicalization and illegal status are $0.9671,0.9719$ and 0.9385

Table 3: Linear Regression of ADDM Database on Historical Cannabis Status.

\begin{tabular}{|c|c|c|c|c|c|c|c|c|}
\hline \multirow[t]{2}{*}{ Parameter } & \multicolumn{4}{|c|}{ Parameters } & \multicolumn{4}{|c|}{ Model } \\
\hline & Est. & Std. Error & t value & $\operatorname{Pr}(>|t|)$ & Adj. R Sq & $\mathrm{F}$ & df & $\mathrm{P}$ \\
\hline \multicolumn{9}{|l|}{ IDEA-Historical Data } \\
\hline \multicolumn{9}{|l|}{ Linear Models } \\
\hline \multicolumn{9}{|l|}{ Log $(\text { Autism_Rate })^{\sim}$ Status } \\
\hline Status_Medical/Legal & 0.179 & 0.0995 & 1.7987 & 0.0756 & 0.0253 & 3.235 & 1,85 & 0.0756 \\
\hline \multicolumn{9}{|c|}{ Log (Autism_Rate $)^{\sim}$ Time+Status } \\
\hline Year & 0.079 & 0.0076 & 10.3666 & $<2.0 \mathrm{E}-16$ & 0.5673 & 57.38 & 2,84 & $<2.0 \mathrm{E}-16$ \\
\hline Status_Medical/Legal & 0.1361 & 0.0664 & 2.0482 & 0.0437 & & & & \\
\hline \multicolumn{9}{|c|}{ Log (Autism_Rate) $)^{\sim}$ Time*Status } \\
\hline Year & 0.079 & 0.0076 & 10.3666 & $<2.0 \mathrm{E}-16$ & 0.5673 & 57.38 & 2,84 & $<2.0 \mathrm{E}-16$ \\
\hline Status_Medical/Legal & 0.1361 & 0.0664 & 2.0482 & 0.0437 & & & & \\
\hline
\end{tabular}

\section{Predicted Quadratic Functions by Cannabis Use Category}

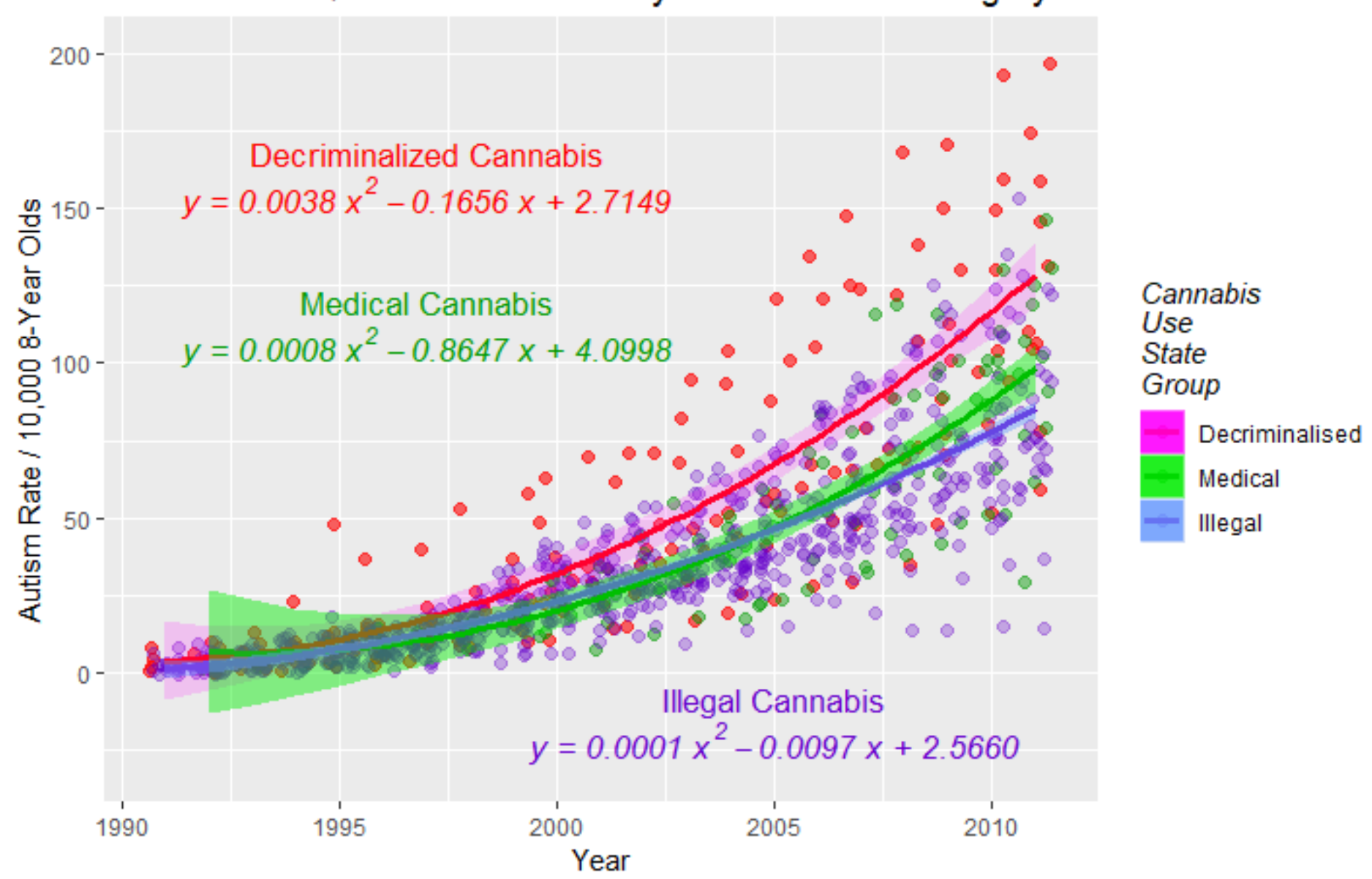

Figure 8: Graph of IDEA autism with historical legal status showing quadratic equations for the best fit regression lines. 
A Predicted Exponential Functions by Cannabis Use

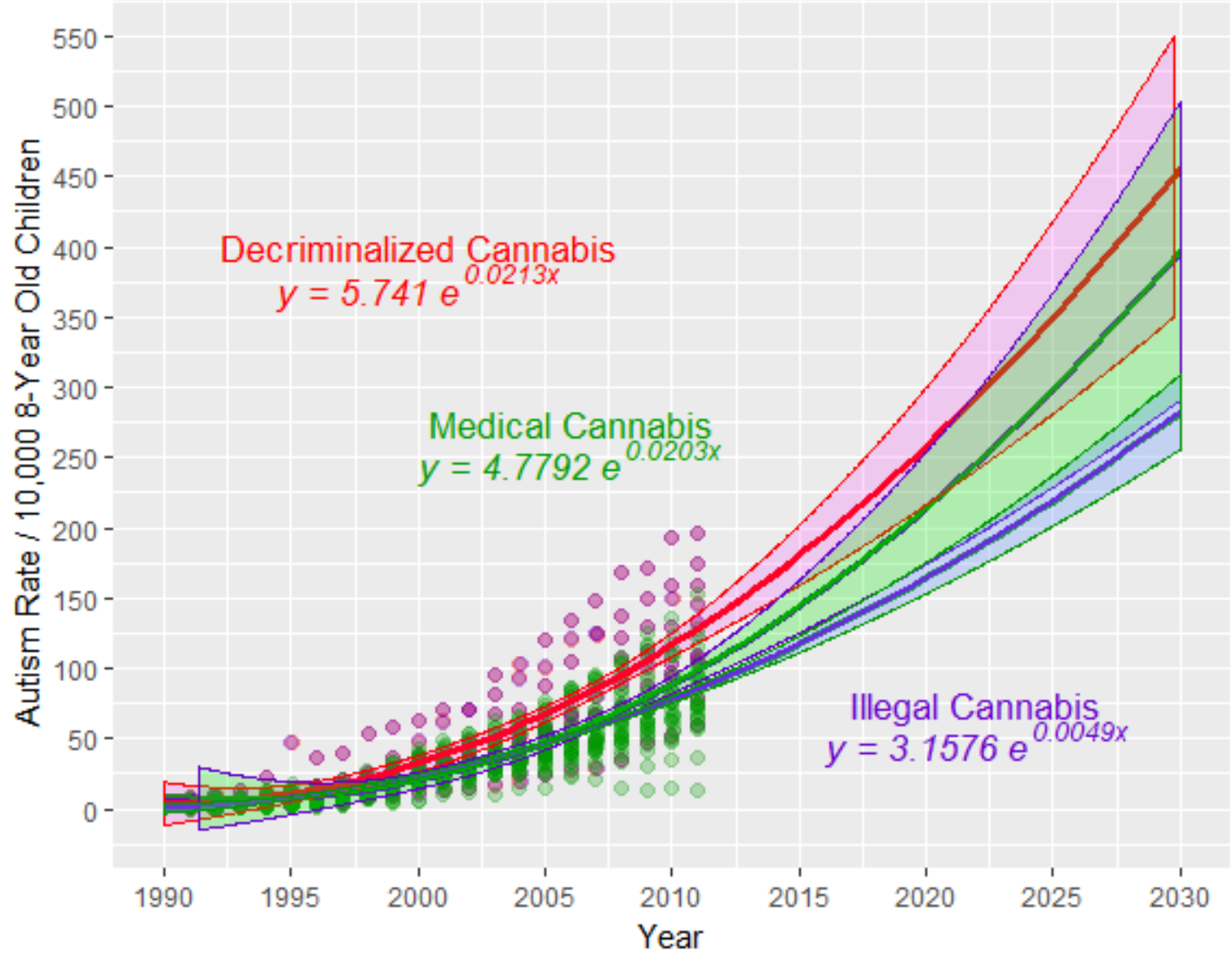

\section{Cannabis \\ Legal \\ Status}

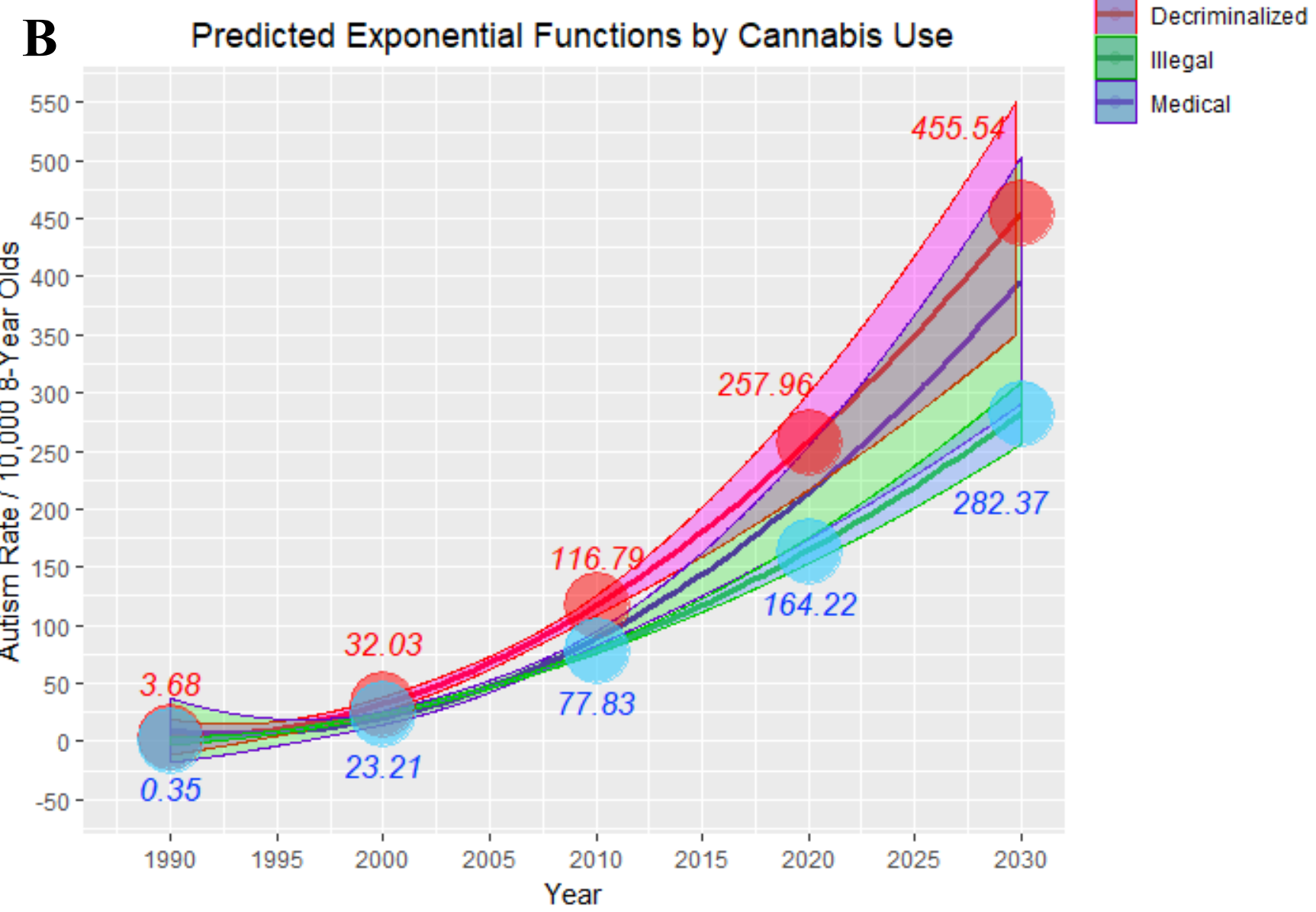

Figure 9: Projections of ASD to 2030 based on presently available IDEA data. A: Includes exponential equations of best fit, B: Placing numbers on the calculated curves at decadal points. 
Table 4: Linear Regression of IDEA Database on Historical Cannabis Status.

\begin{tabular}{|c|c|c|c|}
\hline Year & Decriminalised & Medical & Illegal \\
\hline 1990 & 3.68 & 9.4 & 0.35 \\
\hline 1991 & 3.98 & 7.89 & 1.21 \\
\hline 1992 & 4.84 & 6.96 & 2.38 \\
\hline 1993 & 6.26 & 6.6 & 3.87 \\
\hline 1994 & 8.25 & 6.81 & 5.68 \\
\hline 1995 & 10.8 & 7.6 & 7.81 \\
\hline 1996 & 13.92 & 8.97 & 10.25 \\
\hline 1997 & 17.6 & 10.9 & 13.01 \\
\hline 1998 & 21.85 & 13.41 & 16.09 \\
\hline 1999 & 26.66 & 16.5 & 19.49 \\
\hline 2000 & 32.03 & 20.16 & 23.21 \\
\hline 2001 & 37.97 & 24.39 & 27.24 \\
\hline 2002 & 44.47 & 29.2 & 31.59 \\
\hline 2003 & 51.54 & 34.58 & 36.26 \\
\hline 2004 & 59.17 & 40.53 & 41.24 \\
\hline 2005 & 67.36 & 47.06 & 46.55 \\
\hline 2006 & 76.12 & 54.17 & 52.17 \\
\hline 2007 & 85.44 & 61.85 & 58.11 \\
\hline 2008 & 95.33 & 70.1 & 64.36 \\
\hline 2009 & 105.78 & 78.93 & 70.94 \\
\hline 2010 & 116.79 & 88.33 & 77.83 \\
\hline 2011 & 128.37 & 98.3 & 85.04 \\
\hline 2012 & 140.51 & 108.85 & 92.56 \\
\hline 2013 & 153.22 & 119.97 & 100.41 \\
\hline 2014 & 166.49 & 131.67 & 108.57 \\
\hline 2015 & 180.33 & 143.94 & 117.05 \\
\hline 2016 & 194.72 & 156.79 & 125.85 \\
\hline 2017 & 209.69 & 170.21 & 134.96 \\
\hline 2018 & 225.21 & 184.2 & 144.4 \\
\hline 2019 & 241.31 & 198.77 & 154.15 \\
\hline 2020 & 257.96 & 213.91 & 164.22 \\
\hline 2021 & 275.18 & 229.63 & 174.6 \\
\hline 2022 & 292.96 & 245.92 & 185.31 \\
\hline 2023 & 311.31 & 262.78 & 196.33 \\
\hline 2024 & 330.22 & 280.22 & 207.67 \\
\hline 2025 & 349.7 & 289.24 & 219.32 \\
\hline 2026 & 369.74 & 316.82 & 231.3 \\
\hline 2027 & 390.34 & 335.99 & 243.59 \\
\hline 2028 & 411.51 & 355.72 & 256.2 \\
\hline 2029 & 433.34 & 376.03 & 269.13 \\
\hline 2030 & 455.54 & 396.91 & 282.37 \\
\hline
\end{tabular}

whilst those for quadratic models are $0.8205,0.7949$ and 0.7990 respectively; ANOVA testing is not suitable as degrees of freedom are equal in all models). One notes the very high applicable R-squared $(0.94-0.97)$ for each legal condition implying that the curves of best fit account for nearly all the variance in the trend model.

When these curves are projected outwards into the medium term the data shown in Figure 9B and Table 4 is obtained. Data in Table 4 is highlighted at each decadal point to make it easier to discern the longitudinal trends. One notes a report from the CDC [2] that the 2014 incidence of ASD in the ADDM network was 1.68\%. This is a little above the estimates presented in Table 4 for all three legal conditions, suggesting that the estimates presented there are somewhat underestimates.

Figure 9A presents the applicable exponential equations for the predicted curves and the known data on its left hand side. Figure 9B highlights the growth in ASD rates for the two extreme groups decriminalization and illegal status. Indeed one notes that in 2030 the two rates are predicted to be $455.54 / 10,000$ compared to $282.37 / 10,000$ or $60.75 \%$ larger under the decriminalization regime.

It is noted again that these calculations somewhat underestimate the most recent CDC ADDM estimate of ASD incidence of $1.68 \%$ in 2014 [2]. This in turn implies that these modest projection calculations likely err on the conservative side. As mentioned although these modest projections extend out to 2030, one notes that we are already at 2019. The lag in data acquisition reflects the time needed to diagnose ASD which are often not finalized until 8 years of age. This also gives us pause since if it is accepted that many of the causes of ASD occur during gestational or prenatal life which then this implies that most of the input of genetic and environmental causes have already occurred at this point, since 2019 plus 8 years is 2027 which is almost 2030 already.

\section{DISCUSSION}

The USA appears to be undergoing a significant social transformation in recent years in relation to addiction in general and to cannabis use in particular. Indeed America's addiction epidemics have been at the heart of two recent Surgeons General's reports to the nation $[16,17]$.

The present study confirms that increased rates of US state cannabis use related to increasingly liberal paradigms (medical cannabis, decriminalization and drug legalization) are associated with subsequent increased rates of ASD. Importantly, this correlation was consistently replicated using different indices of ASD are used (IDEA and ADDM) and when different metrics of cannabis legal status are employed (SAMHSA and historical survey data).

This study also demonstrates that most states show a positive relationship between the slope of the cannabis: time and the ASD: time curves on linear regression, geofacet and ggplot2 analysis; Iowa being a notable and prominent exception. Tanglegram analysis confirms that the two slopes are related in a fair to moderate way.

One notes that a few exceptions to the overall pattern do exist in some states. We feel that this may reflect the operation of other complex factors since it seems clear that many environmental and hereditary factors may well interfere with brain development.

The rich IDEA dataset also lends itself to medium term extrapolation. The historically quadratic ASD epidemics appear to be undergoing exponential transformation at present. The projection calculated is numerically somewhat below the latest CDC ADDM figure of $1.68 \%$ in 2014, but nevertheless shows that by 2030 the rate of ASD in cannabis decriminalized states is likely to be more than $60 \%$ higher than that in states where cannabis is not legal in any respect. The real nature of the cannabis effect is likely more significant than suggested by this analysis, as cannabis use is reported to be rising even in jurisdictions where it is presently illegal [10]. Notwithstanding the provisional nature 
of any such projections, it is important to note that much of what will likely occur with autism incidence 2019-2027 has already been set in place given the long incubation time and time to diagnosis of autistic and developmental delays and their largely prenatal and perinatal aetiology.

We show here that at the state level there is a relationship between increased cannabis use and increasing rates of autism; that the slopes of the two epidemics are related; that the epidemic is presently undergoing a transformation from a quadratic growth phase to an exponential growth phase; and noted that this is consistent with numerous mechanistic studies indicating that cannabis is implicated in many key neurodevelopmental processes including myelination, proliferation and migration of foetal neuroblasts, axonal steering and path finding, synapse formation, exuberant outgrowth of the relatively massive human neocortex, fasciculation of white matter fibre tracts and oligodendrocyte physiology, neural stem cell niche maintenance, mitochondrial energetic and metabolic functions, dendritogenesis, microglial and immune maturation, synaptic pruning, and maintenance of the integrity of the genome, epigenome and epitranscriptome [18-44].

Moreover prenatal cannabis exposure has also been linked with many defects of cortical and executive functioning including reduced visual processing, attention span and concentration in all four longitudinal studies which examine this question [4549]. One impressive longitudinal New Zealand study of 1,037 children followed from birth to age 38 years found progressive, serious and dose-related declines in IQ and a global decline in all measures of executive cortical functioning, which accrued with continued use and were obvious to external observers [45]. Cannabis has been shown to impair synapse formation [19,22] and induce dendritic pruning [21] which has been causally linked with the mechanisms of forgetting $[50,51]$ and to adversely affect the slit/robo ratio $[18,52,53]$ a key messenger-ligand pair controlling the extent of exuberant mammalian neocortical development [54,55]. All of these widespread neurocognitive cannabis-induced defects are consistent with its multifarous known mechanisms of action and its intimate involvement in virtually every step of brain and neural network formation.

Overall therefore our results, together with increasing reports from clinicians practising in high-cannabis areas of US [56,57] suggest that an increase in ASD is likely to be one of the more serious, and the commonest implications of increasing the availability of cannabis to the general population and particularly to both male and female adults of reproductive potential.

Reports from the National Births Defects Prevention Network of CDC have previously implicated cannabis use in causing anencephaly, gastroschisis, diaphragmatic hernia and oesophageal stenosis with or without tracheo-oesophageal fistula [58,59]. The American Academy of Pediatrics position statement on the aetiology of non-inherited heart disease previously noted that cannabis is associated with a doubling of the incidence of ventricular septal defect and Ebsteins anomaly [60]. And a large registry-controlled Hawaiian study in 2007 found that the incidence of 21 congenital defects was more common after cannabis exposure [61]. This novel study whose findings were much more serious than others, has since been validated by the latest American experience with atrial septal defect, the experience of many congenital anomalies in Colorado, and a recent experience of phocomelia in France [9].

However since ASD is more common than any of these other disorders it seems likely that it will become by far the most common issue with cannabis teratogenesis and cannabis neuroteratogenesis.

There is a lengthy delay period between birth and diagnosis of ASD. Indeed, given that we are now in 2019 in eight years' time the year will be 2027, so given that much of the aetiology of ASD is believed to occur in or around birth, it would seem that much of this medium term trajectory has already been determined.

It is of interest to consider the generalizability of present findings. Several considerations are pertinent. Firstly USA is a large nation so its experience carries significant epidemiological weight. By many metrics USA is the world's leading nation and exercises considerable financial and cultural prowess. The bulk of cannabis sales occurs over the internet and it is a matter of record that many providers in California, Colorado, Canada and elsewhere have large mail order businesses [62]. Mail order seizures from Colorado show that interstate trafficking ranks in the thousands of kilograms [62]. California is said to grow eight times more cannabis than is consumed intrastate. NSDUH data indicate that in 2017 161,000 pregnant women in USA consumed cannabis and for 69,000 this was reported to be daily or near daily use $[10,13]$. Of particular concern it was recently reported that $69 \%$ of cannabis dispensaries in Colorado recommended cannabis use to pregnant females [11]. Almost 25\% of pregnant females in California recently tested positive or admitted to cannabis use [12]. All these factors point in the same direction and indicate that US trends are likely to have both direct and indirect effects to spread the experience of a cannabis-autism link both within and outside the United States.

The present study has various strengths and weaknesses. Its strengths relate to the use of two major datasets for autism diagnosis and the use of two systems for the categorization of cannabis legal status. Moreover the study is set in the US which arguably has the best data on these parameters. Also the IDEA dataset is of not inconsiderable size being over 1,000 data points. The shortcomings of the study relate to its epidemiological and ecological design. Individual participant level data was not available to this work. These issues would be corrected by the conduct of a prospective case-control design study where data relevant to these matters could be collected prospectively. Since self-report is a generally unreliable basis on which to conduct such investigations more objective measures are required. In this regard the work of the group of David employing hair analysis to assess neonatal toxicological exposure is relevant [63]. It should be noted that it is possible that the cannabis industry may have indirect effects on brain growth and development, as the widespread use of highly potent pesticides to protect cannabis cultivars from animal predation is reported [64]. For example a number of citations have been made of carbofuran use, a highly potent and exquisitely toxic pesticide which has been banned in USA and many nations [64-68].

\section{CONCLUSION}

A substantial literature establishes that brain formation occurs by a complex and intricately orchestrated choreographed "dance" of molecules, genes and epigenetic regulation with new neuroblasts and glial cells coming "on line" and being wired into the expanding neural circuit. The evidence of this study suggests but does not prove that these delicate and spatiotemporally precisely coordinated events are materially, seriously and permanently impaired by prenatal cannabis exposure in the parents.

Our study has shown that ASD is more common in states which host 
more liberal legislative paradigms (decriminalization, legalization and medicalization) relating to cannabis use. This relationship is robust to consideration with different datasets and with different methods of legal status assignment. Extrapolation of current quadratic ASD trends shows exponentiation of the epidemic, with the rate of ASD in cannabis-legal states likely $60 \%$ greater than those in cannabis-illegal states by 2030 under conservative assumptions. These epidemiological level findings are consistent with basic sciences mechanisms which have demonstrated that cannabinoids are critically involved in numerous key aspects of brain and neurological development. Together with the increasingly common presentation of such cases to clinicians practising in localities which see significant numbers of cannabis exposed patients these findings suggest that the autism epidemic will continue to accelerate in the medium term and that the increasing availability of cannabis is likely to have common and unforeseen and potentially serious long-term neurodevelopmental complications. Further detailed mechanistic case-control investigations are required.

\section{FUNDING SOURCE:}

No external funding for this study.

\section{FINANCIAL DISCLOSURE:}

The authors have indicated they have no financial relationships to this article to disclose.

\section{CONFLICT OF INTEREST:}

The authors have indicated they have no potential conflicts of interest to disclose.

\section{CLINICAL TRIAL REGISTRATION:}

Not applicable.

\section{CONTRIBUTORS STATEMENT PAGE}

Dr Reece designed the study, performed the statistical analysis and wrote the first draft.

Prof. Hulse reviewed the manuscript for important intellectual content and revised the draft. He also provided administrative, research support and assisted with statistical advice and oversight.

All authors approved the final manuscript as submitted and agree to be accountable for all aspects of the work.

\section{REFERENCES}

1. Developmental Disabilities Monitoring Network Surveillance Year Principal I, Centers for Disease Control and Prevention (CDC). Prevalence of autism spectrum disorder among children aged 8 years - autism and developmental disabilities monitoring network, 11 sites, United States. MMWR Surveill Summ. 2014;63:1-21.

2. Baio J, Wiggins L, Christensen DL, Maenner MJ, Daniels J, Warren Z, et al. Prevalence of Autism Spectrum Disorder Among Children Aged 8 Years - Autism and Developmental Disabilities Monitoring Network, 11 Sites, United States, 2014. MMWR Surveill Summ. 2018;67:1-23.

3. Nevison C, Blaxill M, Zahorodny W. California Autism Prevalence Trends from 1931 to 2014 and Comparison to National ASD Data from IDEA and ADDM. J Autism Dev Disord. 2018;48:4103-4117.

4. Durkin MS, Maenner MJ, Newschaffer CJ, Lee LC, Cunniff CM,
Daniels JL, et al. Advanced parental age and the risk of autism spectrum disorder. Am J Epidemiol. 2008; 168:1268-1276.

5. Osokine I, Erlebacher A. Inflammation and Autism: From Maternal Gut to Fetal Brain. Trends Mol Med. 2017;23:1070-1071.

6. Wu S, Wu F, Ding Y, Hou J, Bi J, Zhang Z. Advanced parental age and autism risk in children: a systematic review and meta-analysis. Acta psychiatrica Scandinavica. 2017;135:29-41.

7. Foldy C, Malenka RC, Sudhof TC. Autism-associated neuroligin-3 mutations commonly disrupt tonic endocannabinoid signaling. Neuron. 2013;78:498-509.

8. Jung KM, Sepers M, Henstridge CM, Lassalle O, Neuhofer D, Martin $\mathrm{H}$, et al. Uncoupling of the endocannabinoid signalling complex in a mouse model of fragile X syndrome. Nat Commun. 2012;3:1080.

9. Reece AS, Hulse GK. Epidemiological Associations of Various Substances and Multiple Cannabinoids with Autism in USA. Pediatrics. 2019.

10. National Survey on Drug Use and Health (https://www.samhsa.gov/ data/data-we-collect/nsduh-national-survey-drug-use-and-health)

11. Dickson B, Mansfield C, Guiahi M, Allshouse AA, Borgelt LM, Sheeder J, et al. Recommendations From Cannabis Dispensaries About First-Trimester Cannabis Use. Obstet Gynecol. 2018;131:10311038.

12. Young-Wolff KC, Tucker L, Alexeeff S, Armstrong MA, Conway A, Weisner C, et al. Trends in self-reported and biochemically tested marijuana use among pregnant females in california from 2009-2016. JAMA. 2017;318:2490-2491.

13. McCantz-Katz E. 2017 Annual Report Snippets, NSDUH, SAMHSA, USA DHHS - Selected Streamlined Trends. In. Edited by Substance Abuse and Mental Health Services Administration UDoHaHS, Rockville, Maryland: SAMHSA, DHHS, USA. 2018;1:1-78.

14. Hasin DS, Sarvet AL, Cerda M, Keyes KM, Stohl M, Galea S, et al. US Adult Illicit Cannabis Use, Cannabis Use Disorder, and Medical Marijuana Laws: 1991-1992 to 2012-2013. JAM Psychiatry. 2017;74:579. 588.

15. McCantz-Katz E. Urgent and Emerging Issues in Prevention: Marijuana, Kratom and E-Cigarettes. In. Edited by Substance Abuse and Mental Health Services Administration USDoHaHS, Rockville, Maryland: SAMHSA, DHHS, USA. 2019;1:1-43.

16. Substance Abuse and Pregnancy [https://www.acog.org/AboutACOG/ACOG-Departments/State-Legislative-Activities/SubstanceAbuse-and-Pregnancy?IsMobileSet=false]

17. Murthy VH. Ending the Opioid Epidemic - A Call to Action. N Engl J Med. 2016; 375:2413-2415.

18. Alpar A, Tortoriello G, Calvigioni D, Niphakis MJ, Milenkovic I, Bakker J, et al. Endocannabinoids modulate cortical development by configuring Slit2/Robo1 signalling. Nat Commun. 2014;5:4421.

19. Martel G, Uchida S, Hevi C, Chevere-Torres I, Fuentes I, Park YJ, et al. Genetic Demonstration of a Role for Stathmin in Adult Hippocampal Neurogenesis, Spinogenesis, and NMDA Receptor-Dependent Memory. J Neurosci. 2016;36:1185-1202.

20. Tortoriello G, Morris CV, Alpar A, Fuzik J, Shirran SL, Calvigioni DM, et al. Miswiring the brain: Delta9-tetrahydrocannabinol disrupts cortical development by inducing an SCG10/stathmin-2 degradation pathway. EMBO J. 2014;33:668-685.

21. Miller ML, Chadwick B, Dickstein DL, Purushothaman I, Egervari G, Rahman T, et al. Adolescent exposure to Delta(9)-tetrahydrocannabinol alters the transcriptional trajectory and dendritic architecture of prefrontal pyramidal neurons. Mol Psychiatry. 2018. 
22. Szutorisz H, Egervari G, Sperry J, Carter JM, Hurd YL. Crossgenerational THC exposure alters the developmental sensitivity of ventral and dorsal striatal gene expression in male and female offspring. Neurotoxicol Teratol. 2016;58:107-114.

23. Noonan MA, Eisch AJ. Regulation of Adult Neurogenesis by Cannabinoids. Chemistry Today. 2006;24:84-88.

24. Fisar Z, Singh N, Hroudova J. Cannabinoid-induced changes in respiration of brain mitochondria. Toxicology letters. 2014;231:62-71.

25. Harkany T, Horvath TL. (S)Pot on Mitochondria: Cannabinoids Disrupt Cellular Respiration to Limit Neuronal Activity. Cell Metab. 2017;25:8-10.

26. Hebert-Chatelain E, Desprez T, Serrat R, Bellocchio L, Soria-Gomez E, Busquets-Garcia A, et al. A cannabinoid link between mitochondria and memory. Nature. 2016;539:555-559.

27. Hebert-Chatelain E, Reguero L, Puente N, Lutz B, Chaouloff F, Rossignol R, et al. Cannabinoid control of brain bioenergetics: Exploring the subcellular localization of the CB1 receptor. Mol Metab. 2014;3:495-504.

28. Wolff V, Schlagowski AI, Rouyer O, Charles AL, Singh F, Auger C, et al. Tetrahydrocannabinol induces brain mitochondrial respiratory chain dysfunction and increases oxidative stress: a potential mechanism involved in cannabis-related stroke. Biomed Res Int.2015;323-706.

29. Canto C, Menzies KJ, Auwerx J. NAD(+) Metabolism and the Control of Energy Homeostasis: A Balancing Act between Mitochondria and the Nucleus. Cell Metab. 2015;22:31-53.

30. Szutorisz H, Hurd YL. High times for cannabis: Epigenetic imprint and its legacy on brain and behavior. Neurosci Biobehav Rev.2018;85:93101.

31. Prini P, Rusconi F, Zamberletti E, Gabaglio M, Penna F, Fasano M, et al. Adolescent THC exposure in female rats leads to cognitive deficits through a mechanism involving chromatin modifications in the prefrontal cortex. J Psychiatry Neurosci. 2018;43:87-101.

32. Murphy SK, Itchon-Ramos N, Visco Z, Huang Z, Grenier C, Schrott $\mathrm{R}$, et al. Cannabinoid exposure and altered DNA methylation in rat and human sperm. Epigenetics. 2018.

33. Dong C, Chen J, Harrington A, Vinod KY, Hegde ML, Hegde VL. Cannabinoid exposure during pregnancy and its impact on immune function. Cell Mol Life Sci. 2018.

34. Xu C, Loh HH, Law PY. Effects of addictive drugs on adult neural stem/progenitor cells. Cell Mol Life Sci. 2016;73:327-348.

35. Ilyasov AA, Milligan CE, Pharr EP, Howlett AC. The Endocannabinoid System and Oligodendrocytes in Health and Disease. Front Neurosci. 2018;12:733.

36. Gomez O, Sanchez-Rodriguez A, Le M, Sanchez-Caro C, MolinaHolgado F, Molina-Holgado E. Cannabinoid receptor agonists modulate oligodendrocyte differentiation by activating PI3K/Akt and the mammalian target of rapamycin (mTOR) pathways. $\mathrm{Br} \mathrm{J}$ Pharmacol. 2011;163:1520-32.

37. Marinelli C, Bertalot T, Zusso M, Skaper SD, Giusti P. Systematic Review of Pharmacological Properties of the Oligodendrocyte Lineage. Front Cell Neurosci. 2016;10:27.

38. Bernal-Chico A, Canedo M, Manterola A, Victoria Sanchez-Gomez M, Perez-Samartin A, Rodriguez-Puertas R, et al. Blockade of monoacylglycerol lipase inhibits oligodendrocyte excitotoxicity and prevents demyelination in vivo. Glia. 2015;63:163-176.

39. Zalesky A, Solowij N, Yucel M, Lubman DI, Takagi M, Harding IH, et al. Effect of long-term cannabis use on axonal fibre connectivity. Brain. 2012;135:2245-55.
40. Reece AS, Hulse GK. Explaining Contemporary Patterns of Cannabis Teratology. Clinical Pediatrics. 2019;4:146.

41. Reece AS. Cannabis Problematics Include but are not Limited to Pain Management. JAMA 2019.

42. Reece AS, Hulse GK. Gastroschisis and Autism: Dual Canaries in the Californian Coal Mine. JAMA. 2019.

43. Reece AS, Hulse GK. Chromothripsis and epigenomics complete causality criteria for cannabis- and addiction-connected carcinogenicity, congenital toxicity and heritable genotoxicity. Mutat Res. 2016;789:1525.

44. Reece AS, Norman A, Hulse GK. Cannabis Exposure as an Interactive Cardiovascular Risk Factor and Accelerant of Organismal Ageing -A Longitudinal Study. BMJ - Open. 2016;6:e011891-e011900.

45. Meier MH, Caspi A, Ambler A, Harrington H, Houts R, Keefe RS, et al. Persistent cannabis users show neuropsychological decline from childhood to midlife. Proc Natl Acad Sci USA. 2012;109:E2657-2664.

46. Brents L. Correlates and consequences of Prenatal Cannabis Exposure (PCE): Identifying and Characterizing Vulnerable Maternal Populations and Determining Outcomes in Exposed Offspring In: Handbook of Cannabis and Related Pathologies: Biology, Pharmacology, Diagnosis and Treatment. Edited by Preedy V.R. London: Academic Press. 2017;1:160-170.

47. Smith AM, Fried PA, Hogan MJ, Cameron I. Effects of prenatal marijuana on visuospatial working memory: an fMRI study in young adults. Neurotoxicol Teratol. 2006;28:286-295.

48. Smith AM, Longo CA, Fried PA, Hogan MJ, Cameron I. Effects of marijuana on visuospatial working memory: an fMRI study in young adults. Psychopharmacology (Berl). 2010;210:429-438.

49. Smith AM, Mioduszewski O, Hatchard T, Byron-Alhassan A, Fall C, Fried PA. Prenatal marijuana exposure impacts executive functioning into young adulthood: An fMRI study. Neurotoxicol Teratol. 2016;58:53-59.

50. Dejanovic B, Huntley MA, De Maziere A, Meilandt WJ, Wu T, Srinivasan K, et al. Changes in the Synaptic Proteome in Tauopathy and Rescue of Tau-Induced Synapse Loss by C1q Antibodies. Neuron. 2018;100:1322-1336 e1327.

51. Awasthi A, Ramachandran B, Ahmed S, Benito E, Shinoda Y, Nitzan N, et al. Synaptotagmin-3 drives AMPA receptor endocytosis, depression of synapse strength, and forgetting. Science. 2019;363.

52. Lu T, Newton C, Perkins I, Friedman H, Klein TW. Cannabinoid treatment suppresses the T-helper cell-polarizing function of mouse dendritic cells stimulated with Legionella pneumophila infection. J Pharmacol Exp Ther. 2006;319:269-276.

53. Newton CA, Chou PJ, Perkins I, Klein TW. $\mathrm{CB}(1)$ and $\mathrm{CB}(2)$ cannabinoid receptors mediate different aspects of delta-9tetrahydrocannabinol (THC)-induced $\mathrm{T}$ helper cell shift following immune activation by Legionella pneumophila infection. J Neuroimmune Pharmacol. 2009;4:92-102.

54. Cardenas A, Villalba A, De Juan Romero C, Pico E, Kyrousi C, Tzika AC, et al. Evolution of Cortical Neurogenesis in Amniotes Controlled by Robo Signaling Levels. Cell. 2018;174:590-606.

55. Yeh ML, Gonda Y, Mommersteeg MT, Barber M, Ypsilanti AR, Hanashima C, et al. Robo1 modulates proliferation and neurogenesis in the developing neocortex. J Neurosci. 2014;34:5717-5731.

56. Stuyt E. The Problem with the Current High Potency THC Marijuana from the Perspective of an Addiction Psychiatrist. Mo Med. 2018;115:482-486.

57. Finn K: Why Marijuana Will Not Fix the Opioid Epidemic. Mo Med. 2018;115:191-193. 
58. Van Gelder MMHJ, Donders ART, Devine O, Roeleveld N, Reefhuis J. Using bayesian models to assess the effects of under-reporting of cannabis use on the association with birth defects, national birth defects prevention study, 1997-2005. Paediatr Perinat Epidemiol. 2014;28:424-433.

59. Van Gelder MMHJ, Reefhuis J, Caton AR, Werler MM, Druschel CM, Roeleveld N. Maternal periconceptional illicit drug use and the risk of congenital malformations. Epidemiology. 2009;20:60-66.

60. Jenkins KJ, Correa A, Feinstein JA, Botto L, Britt AE, Daniels SR, et al. American Heart Association Council on Cardiovascular Disease in the Y: Noninherited risk factors and congenital cardiovascular defects: current knowledge: a scientific statement from the American Heart Association Council on Cardiovascular Disease in the Young: endorsed by the American Academy of Pediatrics. Circulation. 2007;115:2995-3014.

61. Forrester MB, Merz RD. Risk of selected birth defects with prenatal illicit drug use, Hawaii, 1986-2002. J Toxicol Environ Health A. 2007;70:7-18.

62. Rocky Mountain High Drug Trafficking Area: The Legalization of Marijuana in Colorado: The Impact. 2017;1:1-168.
63. David AL, Holloway A, Thomasson L, Syngelaki A, Nicolaides K, Patel RR, et al. A case-control study of maternal periconceptual and pregnancy recreational drug use and fetal malformation using hair analysis. PLoS One. 2014;9:e111038.

64. Mills D. The Office of Distruict 4 Supervisor CC, California,: Cultivating Disaster: The Effects of Cannabis Cultivation on the Environment of Calaveras County. Calaveras County, California, USA. 2018;1:61.

65. Carlson BM. Human Embryology and Developmental Biology. Philadelphia: Elsevier. 2014;1.

66. Borrell V, Cardenas A, Ciceri G, Galceran J, Flames N, Pla R, et al. Slit/Robo signaling modulates the proliferation of central nervous system progenitors. Neuron. 2012;76:338-352.

67. Boulanger LM. Immune proteins in brain development and synaptic plasticity. Neuron. 2009;64:93-109.

68. Carpentier PA, Palmer TD. Immune influence on adult neural stem cell regulation and function. Neuron. 2009;64:79-92. 